\title{
The association between sleep-disordered breathing and magnetic resonance imaging findings in a pediatric cohort with Chiari 1 malformation
}

\author{
Reshma Amin MD MSc ${ }^{1,2}$, Priya Sayal BHSC ${ }^{1}$, Aarti Sayal ${ }^{1}$, Colin Massicote RPSGT ${ }^{1}$, Robin Pham ${ }^{1}$, \\ Suhail AI-Saleh MD MSc ${ }^{1,2}$, James Drake BSE MBBCh $\mathrm{MSc}^{2,3}$, Indra Narang MBBCH MD ${ }^{1,2}$
}

R Amin, P Sayal, A Sayal, et al. The association between sleep disordered breathing and MRI findings in a pediatric cohort with Chiari 1 malformation. Can Respir J 2015;22(1):31-36.

BACKGROUND: The prevalence of sleep-disordered breathing (SDB) reported in the literature for Chiari malformation type 1 (CM1) is uniformly high (24\% to 70\%). In Canada, there is limited access to pediatric polysomnography (PSG). Therefore, the identification of clinical features would be invaluable for triaging these children.

OBJECTIVE: To identify demographic features, clinical symptoms/signs and radiological findings associated with SDB in a large pediatric cohort with CM1.

METHODS: A retrospective review was conducted on children with CM1 who underwent baseline PSG. Data were collected on patient demographics (age, sex, weight, height, body mass index), clinical symptoms (chart review and clinical questionnaires), diagnostic imaging of the brain and cervicothoracic spine, and medical history at the time of referral.

RESULTS: A total of 68 children were included in the review. The mean $( \pm$ SD) age of the children at the time of PSG was $7.33 \pm 4.01$ years; $56 \%$ $(n=38)$ were male. There was a $49 \%$ prevalence of SDB in this cohort based on the overall apnea-hypopnea index. Obstructive sleep apnea was the predominant type of SDB. Tonsillar herniation was significantly correlated with obstructive apnea-hypopnea index $(r=0.24 ; \mathrm{P}=0.036)$.

CONCLUSIONS: A direct relationship between the degree of cerebellar tonsillar herniation and obstructive sleep apnea was demonstrated. However, further prospective studies that include neurophysiological assessment are needed to further translate the central nervous system imaging findings to predict the presence of SDB.

Key Words: Chiari 1 malformation; Pediatric; Sleep-disordered breathing

Chiari malformation (CM) type 1 (CM1), first described by Chiari in 1891, is currently defined as the caudal descent of the cerebellar tonsils by $\geq 5 \mathrm{~mm}$ below the plane of the foramen magnum. Compression at the level of the craniovertebral junction may result in neuronal dysfunction of the brainstem, cerebellum, cranial nerves and/or the upper spinal cord. There may also be mechanical obstruction of the cerebrospinal fluid (CSF) circulation, resulting in rerouting of the CSF fluid into the spinal cord and brainstem, syringomyelia and syringobulbia (1). Given the bulbar location of the respiratory control centres, sleep-disordered breathing (SDB) has been demonstrated to be a serious clinical consequence of CM1, with documented risk of mortality (2). Undiagnosed or untreated SDB is associated with significant morbidity including cognitive impairment and poor school performance, growth failure, systemic and pulmonary hypertension, as well as endothelial dysfunction (3-12).

The prevalence of SDB reported in the literature for CMs is uniformly high $(24 \%$ to $70 \%)(1,13-16)$. However, the cohorts previously reported included a heterogeneous population with respect to CM type and age (ie, adult versus mixed pediatric and adult cohorts). Based on the existing literature, which is largely derived from adult

\section{L'association entre les troubles respiratoires du sommeil et les résultats de l'imagerie par résonance magnétique dans une cohorte d'âge pédiatrique ayant une malformation de Chiari de type 1}

HISTORIQUE : La prévalence de troubles respiratoires du sommeil (TRS) est toujours élevée ( $24 \%$ à $70 \%$ ) dans les publications en cas de malformation de Chiari de type $1(\mathrm{MC} 1)$. Au Canada, l'accès à la polysomnographie pédiatrique (PSP) est limité. Par conséquent, dans le cadre du triage de ces patients, il serait inestimable d'en déterminer les caractéristiques cliniques.

OBJECTIF : Déterminer les caractéristiques démographiques, les signes et symptômes cliniques et les résultats radiologiques associés aux TRS dans une vaste cohorte d'âge pédiatrique ayant une $\mathrm{MC1}$.

MÉTHODOLOGIE : Des chercheurs ont procédé à une analyse rétrospective sur des enfants atteints d'une MC1 qui avaient subi une PSP de référence. Ils ont colligé des données sur la démographie des patients (âge, sexe, poids, taille, indice de masse corporelle), les symptômes cliniques (examen de dossiers et questionnaires cliniques), l'imagerie diagnostique du cerveau et de la colonne cervicothoracique et les antécédents médicaux au moment de l'aiguillage.

RÉSULTATS : Au total, 68 enfants, dont $56 \%$ de garçons ( $\mathrm{n}=38$ ), ont participé à l'analyse. Ils avaient un âge moyen ( \pm ÉT) de 7,33 $\pm 4,01$ ans au moment du PSP. Dans cette cohorte, la prévalence de TRS, fondée sur l'indice global d'apnée-hypopnée, s'élevait à $49 \%$. Le type de TRS prédominant était l'apnée obstructive du sommeil. La hernie des amygdales était corrélée de manière significative avec l'indice global d'apnée obstructive-hypopnée $(\mathrm{r}=0,24 ; \mathrm{P}=0,036)$

CONCLUSIONS : Les chercheurs ont démontré une relation directe entre le degré de hernie des amygdales cérébelleuses et l'apnée obstructive du sommeil. Cependant, il faudra effectuer d'autres études prospectives incluant une évaluation neurophysiologique pour mieux interpréter les résultats de l'imagerie du système nerveux central afin de prédire la présence de TRS.

data, screening of all children with known CM1 with polysomnograhy (PSG) is suggested. Access to pediatric PSG is currently limited by an 18-month wait period for PSG at our centre alone, with similar wait times across Canada. Therefore, the identification of clinical symptoms or signs and/or radiological characteristics would be invaluable for identifying high-risk children with CM1 and triaging them for PSG, thus minimizing the time on a wait list. Therefore, our aim was to identify demographic features, clinical symptoms/signs or radiological findings associated with SDB in a large pediatric cohort with CM1.

\section{METHODS}

A retrospective review of children with CM1 who underwent baseline PSG at The Hospital for Sick Children (Toronto, Ontario) between January 1, 2006 and July 1, 2013 was conducted. Patients were excluded if they were on respiratory technology during the initial PSG during the study period. The health records of each patient were systematically reviewed. Data regarding patient demographics (age, sex, weight, height, body mass index), clinical symptoms (chart review and clinical questionnaires), diagnostic imaging of the brain

\footnotetext{
${ }^{1}$ Division of Respiratory Medicine, Department of Paediatrics, The Hospital for Sick Children; ${ }^{2}$ University of Toronto; ${ }^{3}$ Department of

Neurosurgery, The Hospital for Sick Children, Toronto, Ontario

Correspondence: Dr Reshma Amin, The Hospital for Sick Children, 555 University Avenue, Toronto, Ontario M5G 1 X8.

Telephone 416-813-6346, fax 416-813-6246, e-mail reshma.amin@sickkids.ca
} 


\section{TABLE 1}

\section{Descriptive statistics for Chiari malformation type I} patients in the study population $(n=68)$

\begin{tabular}{lc}
\hline Characteristic & Chiari I patients \\
\hline Age at time of PSG, years, mean \pm SD & $7.33 \pm 4.01$ \\
Male sex, n (\%) & $38(56)$ \\
Weight, kg, median (IQR) & $24(15.88-37.13)$ \\
Height, cm, mean \pm SD & $119.7 \pm 25.52$ \\
Body mass index*, percentile, median (IQR) & $75.50(56.00-91.00)$ \\
Previous adenoidectomy or tonsillectomy, n (\%) & $13(19)$ \\
Previous decompression surgery, n (\%) & $10(15)$ \\
\hline${ }^{*}$ Body mass index data not available for four children because they were \\
younger than two years of age at the time of the study. IQR Interquartile range
\end{tabular}

and cervicothoracic spine, and medical history at the time of referral were collected. In addition, surgical and medical interventions that occurred based on PSG results were recorded, in addition to patient disposition at the end of the study period.

All patients underwent the same magnetic resonance imaging (MRI) protocol with 1.5T sagittal-axial T1-T2 sequences of the brain and cervicothoracic spine. CM1 was defined as tonsillar herniation $\geq 5 \mathrm{~mm}$ below the foramen magnum on mid sagittal sequences (15). Syringomyelia was defined as spinal or medullary cord cavity with contents similar to CSF on T1-T2 sequences

All PSGs were conducted according to the American Academy of Sleep Medicine 2007 manual for the scoring of sleep and associated events with a computer based software system (XL-TEK, Canada) (17). A standard overnight PSG included a four-lead electroencephalogram (C3, C4, O1 and O2), two bilateral electro-oculogram leads referenced to A1 or A2, and one submental and two tibial electromyograms (EMG). Respiratory measurements included chest wall and abdominal movement using inductance pneumography; airflow using a nasal cannula connected to a nasal pressure airflow transducer (Braebon, Canada); oxygen saturation using a pulse oximeter (Massimo, USA); transcutaneous carbon dioxide $\left(\mathrm{tcCO}_{2}\right)$ measurement using a carbon dioxide sensor (LINDE, Germany); and end tidal carbon dioxide $\left(\right.$ et $\left.\mathrm{CO}_{2}\right)$ measurements using a capnometer (Capnocheck, Smiths Medical, United Kingdom). Video and audio recordings were obtained for each study. Sleep architecture was assessed using standard techniques. Information obtained from each PSG included sleep-onset latency and rapid eye movement (REM)onset latency, total sleep time, sleep efficiency, time spent in each sleep stage (percentage), and number and classification of arousals and snoring. All respiratory events were also scored according to the respiratory rules for children in the American Academy of Sleep Medicine guidelines. Recorded respiratory data included counts and indexes of the following events: obstructive apneas, obstructive hypopneas, central apneas and mixed apneas during sleep. The obstructive apnea-hypopnea index (OAHI) was defined as the number of obstructive apneas, hypopneas and mixed apneas per hour. The central apnea index (CAI) was defined as the number of central apneas per hour. Hypoventilation was defined as an etCO $\mathrm{CO}_{2}$ or $\mathrm{tcO}_{2}$ level $>50 \mathrm{mmHg}$ for $\geq 25 \%$ of the night. Obstructive sleep apnea (OSA) was defined as an OAHI $\geq 2 / h$. Moderate-severe OSA was defined as OAHI $\geq 5 / h$. Central sleep apnea (CSA) was defined as a CAI $\geq 5 / \mathrm{h}$. Moderatesevere CSA was defined as CAI $\geq 5 / \mathrm{h}$. Combined sleep apnea was defined as a combined apnea-hypopnea index $(\mathrm{AHI}) \geq 2 / \mathrm{h}$. Moderatesevere combined sleep apnea was defined as $\mathrm{AHI} \geq 5 / \mathrm{h}$.

Descriptive statistics were used to summarize the study results. Results were presented as mean \pm SD for normally distributed data or as the median and interquartile range (IQR) for non-normally distributed data. Bivariate relationships were analyzed using the $\chi^{2}$ test and expressed as RR (95\% CI) for categorical variables and using Spearman correlation coefficients for continuous variables. Statistical analysis was performed using GraphPad Prism version 5.0 (GraphPad, USA).
TABLE 2

Classification of sleep-disordered breathing (SDB) abnormalities in 33 children with abnormal polysomnography (PSG) results

\begin{tabular}{|c|c|}
\hline Type of SDB & n (\%) \\
\hline \multicolumn{2}{|l|}{ Obstructive sleep apnea } \\
\hline Mild $(\mathrm{OAHI} \geq 2>5 / \mathrm{h})$ & $4(6)$ \\
\hline Moderate-severe $(\mathrm{OAHI} \geq 5 / \mathrm{h})$ & $12(18)$ \\
\hline \multicolumn{2}{|l|}{ Central sleep apnea } \\
\hline Moderate-severe (CAI $\geq 5 / h)$ & $12(18)$ \\
\hline \multicolumn{2}{|l|}{ Hypoventilation } \\
\hline $\mathrm{EtCO}_{2}$ or $\mathrm{tcCO}_{2}>50 \mathrm{mmHg}$ for $\geq 25 \%$ of total sleep time & $6(9)$ \\
\hline \multicolumn{2}{|l|}{ Total AHI } \\
\hline Mild SDB (Total AHI $\geq 2>5 / h$ ) & $10(15)$ \\
\hline Moderate-severe SDB (total $\mathrm{AHI} \geq 5 / \mathrm{h}$ ) & $20(29)$ \\
\hline \multicolumn{2}{|l|}{ Abnormal PSG } \\
\hline Total $\mathrm{AHI} \geq 2 / \mathrm{h}$ and/or hypoventilation & $33(49)$ \\
\hline
\end{tabular}

AHI Apnea-hypopnea index; CAl Central sleep apnea index; $\mathrm{EtCO}_{2}$ End tidal carbon dioxide; $\mathrm{OAHI}$ Obstructive $\mathrm{AHI}$; $t \mathrm{CO}_{2}$ Transcutaneous carbon dioxide

The present study was approved by the Research Ethics Board at The Hospital for Sick Children (REB \#1000025247), University of Toronto, Toronto, Ontario.

\section{RESULTS}

Seventy-six children with CM1 were referred to the sleep laboratory for PSG during the study period. Eight children were excluded because their PSG was performed while on technology (supplemental oxygen, continuous positive airway presssure, bilevel positive airway pressure, or tracheostomy and invasive ventilation). A total of 68 children were included in the review.

The mean $( \pm \mathrm{SD})$ age of the children at the time of PSG was $7.33 \pm 4.01$ years; $56 \%(n=38)$ were male. Before PSG, $10(15 \%)$ children had previously undergone surgical decompression for the CM. Thirteen (19\%) of the children had undergone either a previous adenoidectomy or tonsillectomy (Table 1). Forty (59\%) of the children with CMs had a coexisting condition (eg, asthma, epilepsy).

\section{PSG characteristics}

The PSG results are summarized in Tables 2 and 3. There were significant differences in the percentage of REM and non-REM sleep between those with and without SDB. Sleep architecture was maintained within the range of normal in the majority of patients There was a $49 \%$ prevalence of SDB in the cohort based on the overall AHI (Table 2). Breathing during sleep was mildly abnormal (AHI $\geq 2 / \mathrm{h}$ ) in $10(15 \%)$ children and moderately/severely abnormal (AHI $\geq 5 / \mathrm{h}$ ) in 20 (29\%). Among the 20 patients with moderate-severe SDB, median AHI was 12.45 (IQR 7.03 to 30.9). Twelve (18\%) patients had moderate-severe OSA and 12 (18\%) had moderate-severe CSA. Two patients had both central $\mathrm{AHI}$ and $\mathrm{OAHI} \geq 5 / \mathrm{h}$. The oxygen saturation nadir significantly correlated with both the OAHI and central AHI. However, the strongest correlation for the oxygen saturation nadir was with the overall AHI $(\mathrm{r}=-0.53 ; \mathrm{P}<0001)$. Six $(9 \%)$ of children in the CM1 cohort had evidence of hypoventilation on PSG. Only one child had a maximum $\mathrm{PCO}_{2} \geq 60 \mathrm{mmHg}$ on the night of PSG.

The OAHI, CAI and total AHI were compared among the 10 patients who had undergone decompression before the first PSG and the 58 patients who had not. There were no significant differences among the three indexes. However, using the Mann-Whitney test, the CAI showed a trend toward a higher index in the patients who had been previously decompressed compared with those who had not (median 1.90 [IQR 0.65 to 6.1] versus 0.5 [IQR 0 to 1.6 ]; $\mathrm{P}=0.06$ ). 


\begin{tabular}{|c|c|c|c|}
\hline \multirow[b]{2}{*}{ Characteristic } & \multicolumn{2}{|c|}{ SDB } & \multirow[b]{2}{*}{$\mathbf{P}$} \\
\hline & $\begin{array}{c}\text { Yes } \text { (total } A H I \geq 2 / h \text { and/or nocturnal } \\
\text { hypoventilation) }(n=33)\end{array}$ & $\begin{array}{c}\text { No (total } \mathrm{AHI}<2 / \mathrm{h} \text { and no nocturnal } \\
\text { hypoventilation) }(\mathrm{n}=35)\end{array}$ & \\
\hline \multicolumn{4}{|l|}{ Sleep architecture } \\
\hline Sleep efficiency, \% & $87.45(80.93-92.78)$ & $85.80(77.65-91.80)$ & 0.42 \\
\hline Non-REM sleep, \% & $79.25(75.13-83.43)$ & $81.70(78.85-86.75)$ & 0.027 \\
\hline REM sleep, \% & $20.75(16.58-24.88)$ & $18.30(13.25-21.15)$ & 0.027 \\
\hline \multicolumn{4}{|l|}{ Respiratory events } \\
\hline Obstructive $\mathrm{AHI}$ & $1.9(0.7-5.7)$ & $0.3(0-0.8)$ & $<0.0001$ \\
\hline Central apnea index & $2.4(0.63-8.95)$ & $0.3(0-0.75)$ & $<0.0001$ \\
\hline Total AHI & $7.45(2.83-14.55)$ & $0.8(0.45-1.3)$ & $<0.0001$ \\
\hline \multicolumn{4}{|l|}{ Gas exchange } \\
\hline Nadir $\mathrm{O}_{2}$ desaturations & 86.5 (80.25-90.98) & $92.3(90.65-94)$ & $<0.0001$ \\
\hline
\end{tabular}

Data presented as median (interquartile range) unless otherwise indicated. AHI Apnea-hyponea index; REM Rapid eye movement

\section{Clinical symptoms}

Information regarding clinical symptoms at the time of the referral for PSG was obtained from a combination of parental sleep questionnaires that were completed the night of the PSG as well as by systematic chart review. At the time of referral for PSG, all children except for two had respiratory symptoms, with mouth breathing being the most prevalent (Appendix 1). Snoring was present in $63 \%(n=43)$ of the study population. There were no significant differences in the OAHI or CAI between snoring and nonsnoring groups $(\mathrm{P}=0.11$ and $\mathrm{P}=0.99$, respectively). Eighty-five percent $(n=58)$ of the children with CM1 had at least one neurological/developmental finding at the time of PSG. Thirty-four (50\%) children experienced morning headaches, the most prevalent neurological symptom in the cohort (Appendix 1). There were no significant differences in the OAHI or CAI in children with or without headaches $(\mathrm{P}=0.34)$. Of the 35 children with normal sleep studies, only one was asymptomatic.

\section{MRI findings}

The MRI findings are summarized in Table 4. For patients with multiple previous MRIs, the MRI temporally closest to the PSG was reported. The median number of days between PSG and MRI for the 68 children was 41.5 (IQR -34.8 to 173.3 ). The median of cerebellar tonsillar herniation was $11 \mathrm{~mm}$ (IQR $7.8 \mathrm{~mm}$ to $15.3 \mathrm{~mm}$ ). Other than hydrocephalus $(\mathrm{P}=0.02)$, there were no significant differences in MRI features between those with and without SDB (Table 4). However, tonsillar herniation was significantly correlated with $\mathrm{OAHI} / \mathrm{h}(\mathrm{r}=0.24$; $\mathrm{P}=0.036$ ) but not the $\mathrm{CAI} / \mathrm{h}$ or the total $\mathrm{AHI} / \mathrm{h}$ (Figure 1). A tonsillar herniation cut-off $\geq 20 \mathrm{~mm}$ was associated with the presence of OSA $(\mathrm{P}=0.008)$. There was a significant correlation between total AHI and syrinx $(r=0.28 ; P=0.014)$. This association was persistent even after the 10 children with previous decompression were removed from the analysis $(\mathrm{r}=0.36 ; \mathrm{P}=0.04)$. Total $\mathrm{AHI} / \mathrm{h}, \mathrm{OAHI} / \mathrm{h}$ and $\mathrm{CAI} / \mathrm{h}$ were not significantly different between children with and without effacement on neuroimaging (Appendix 2).

\section{Treatment and outcomes}

Before the study, 10 (15\%) children had previously undergone posterior fossa decompression and 13 (19\%) had undergone adenoidectomy, tonsillectomy or both. Of the 33 children with abnormal PSG results, 17 had received definitive surgical or medical management. Seven (29\%) progressed to have a posterior fossa decompression. Four children underwent tonsillectomy or adenotonsillectomy, two were prescribed bilevel positive pressure ventilation and four were prescribed continuous positive airway pressure. Notably, CM1 was newly diagnosed in three of $24(13 \%)$ children with moderate-severe SDB because the PSG findings prompted central nervous system (CNS) imaging.
TABLE 4

Magnetic resonance imaging findings for Chiari malformation type 1 children with and without sleep-disordered breathing (SDB)

\begin{tabular}{lccc}
\hline \multirow{2}{*}{ Finding } & \multicolumn{2}{c}{ SDB } & P \\
\cline { 2 - 3 } & Yes $(\mathbf{n}=\mathbf{3 3})$ & No $(\mathbf{n}=\mathbf{3 5})$ & $\mathbf{0}$ \\
\hline Tonsillar descent below foramen & $13.5 \pm 6.2$ & $12.4 \pm 5.1$ & 0.40 \\
magnum, mm, mean \pm SD & & & \\
Cerebrospinal fluid effacement & 13 & 20 & 0.16 \\
Syrinx & 14 & 11 & 0.45 \\
Hydrocephalus & 5 & 0 & 0.02 \\
Velopharyngeal shunt & 2 & 2 & 1 \\
\hline
\end{tabular}

Data presented as $n$ unless otherwise indicated

\section{DISCUSSION}

To our knowledge, the present study describes clinical, PSG and radiographic findings in the largest reported pediatric CM1 cohort. The prevalence of SDB in $49 \%$ of the CM1 cohort referred for PSG is extremely high and $>10$-fold higher than the general pediatric population (18-20). We report a prevalence of SDB similar to the Dauvilliers et al (15), which included 20 children with CM1 and CM2, as well as two adult studies $(1,14)$.

Our data suggest that MRI findings - but not clinical symptoms correlate with the presence of SDB based on PSG. Therefore, clinicians may be able to use some of the MRI findings to triage children with CM1 for PSG. The OAHI correlated with the extent of cerebellar tonsillar descent below the foramen magnum. In particular, a tonsillar herniation cut-off $\geq 20 \mathrm{~mm}$ was associated with OSA. We also found that the presence of a syrinx correlated with total AHI. However, we identified a lower prevalence of syrinx compared with other published pediatric and adult studies $(1,14)$. This was true even when the 10 children with previous posterior fossa decompression were excluded from the analysis (19 of 68 [28\%]). Losurdo et al (16) also recently demonstrated a relationship between OSA and the presence of a syrinx. A syrinx represents a delayed expansion and potential injury to the spinal cord, and is likely progressive over time (14). Given the association of syrinx with SDB in our study as well as others, one would expect worsening SDB and an increased incidence of syrinx with increasing age. Therefore, the young median age of our cohort may account for the lower incidence of syrinx on CNS imaging. We did not find a significant difference in SDB between children with and without CSF effacement on neuroimaging, as did Dhamija et al (21), who demonstrated a significantly higher CAI among children with effacement. However, the numbers in the comparator groups are small 


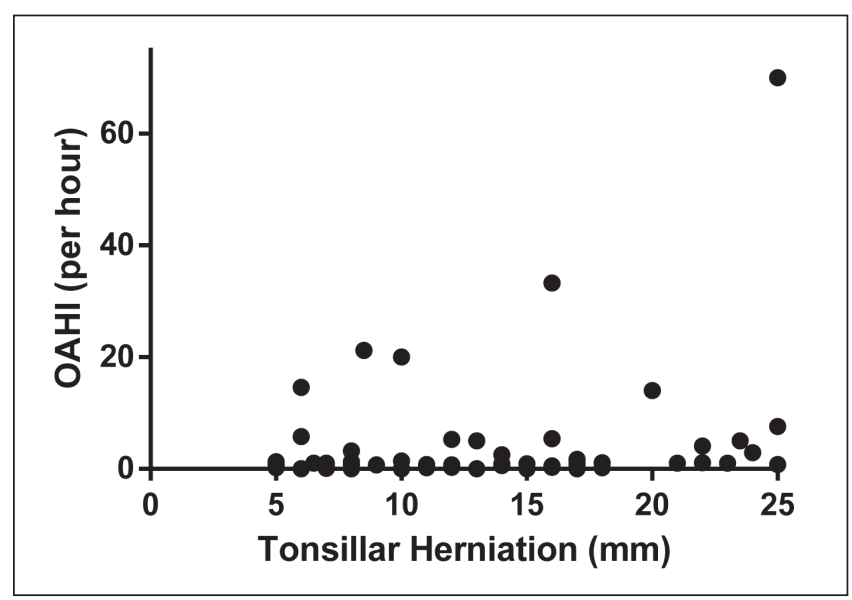

Figure 1) The correlation between obstructive apnea-hypopnea index $(\mathrm{OAHI})$ and the extent of tonsillar herniation on brain magnetic resonance imaging

and larger numbers would be helpful to correlate the structural findings on CNS imaging with the presence of SDB. A subset of children with SDB in our cohort had hydrocephalus, whereas no children had hydrocephalus in the non-SDB cohort. Losurdo et al (16) also demonstrated a relationship between the presence of hydrocephalus and SDB in their pediatric CM1 cohort.

Central apnea is conventionally regarded as the most frequent respiratory complication of $\mathrm{CM} 1$; however, more recent literature, including our own study, challenges this conventional belief. SDB was also shown to be predominantly obstructive in the study by Dauvilliers et al (15) involving a pediatric cohort of CM1 and CM2, Khatwa et al's (22) pediatric CM1 cohort as well as in larger CM1 cohorts of 25 and 32 adults, respectively $(1,14)$.

SDB resulting from CM1 is believed to occur as a result of two primary mechanisms: abnormalities in respiratory control (ie, CSA) and upper airway dysfunction (ie, OSA). Suggested mechanisms for CSA include: lack of functional chemoreceptor afferents because of injury to the cranial nerve; insensitivity of peripheral chemoreceptors due to brainstem involvement; compression of phrenic motor neurons in the anterior horn of the cervical spinal cord because of a syrinx or compromised vascular supply to the brainstem; bulbar compression of the respiratory centre by an odontoid apophysis or by downward displacement of the cerebellar tonsils; and/or mechanical stimulation of chemoreceptors leading to overactivity $(2,23-28)$. On the other hand, OSA is believed to result from weakness of the pharyngeal and dilating laryngeal muscles (29). This may be the result of variability in the neural output to the upper airway dilators, dyssynchrony between neural output to upper airway and ventilatory pump muscles, impairment of upper airway reflexes and/or vocal cord paralysis (23). The correlation between $\mathrm{OAHI}$ and the extent of cerebellar tonsillar descent below the foramen magnum suggests a more direct relationship between herniation depth and brainstem dysfunction. Khatwa et al (22) also found that children with SDB were more likely to exhibit a greater length of herniation compared with children without SDB. In contrast, the etiology of CSA appears to be multifactorial and not explained by this simple relationship alone. However, further prospective studies using neurophysiological investigations, such as transcranial magnetic stimulation, would be helpful to mediate the structural findings on CNS imaging with the functional output of PSG (30).

There are multiple reasons for clinicians to recognize the association of CM1 and SDB. The mean age of the children in our cohort was 7.33 years, which challenges the classical belief that CM1 is a disease of adult onset. Eighteen percent of children in the present study had severe OSA, which is important to highlight because most clinicians are not aware that a CM1 is part of the differential diagnosis for OSA.
Furthermore, unexplained SDB may be secondary to an occult CM1, as observed in three children in our cohort. A lack of timely diagnosis and management can lead to untreated SDB, with a risk for significant morbidity and mortality. Children with CM1 are at an increased risk for neurocognitive complications, including reduced intellectual quotient scores and behavioural difficulties, and may also rarely be at increased risk for adverse cardiorespiratory outcomes and death (31-33). Clinical sleep history and physical examination are not sufficiently sensitive or specific to establish a diagnosis of sleep apnea in patients with CM1 (34). All but one of the children in our cohort with normal PSG remained symptomatic. Therefore, children with CM1 require systematic screening for SDB via PSG. A PSG is needed not just to diagnose SDB, but also to determine its severity, as well as differentiate among OSA, CSA or mixed apnea. Management decisions are based on this key distinction. An adenotonsillectomy is the first-line treatment for OSA and mixed apnea, but not for CSA alone.

We demonstrated that a greater degree of tonsillar herniation - a cut-off $\geq 20 \mathrm{~mm}$ of herniation - as well as the presence of a syrinx is associated with SDB. This suggests that there may be a role for MRI findings, in part, to help triage children with CMs for a PSG given the 18-month wait period for PSG in our tertiary pediatric centre, which reflects the limited access to pediatric PSG across the country. However, further prospective study in a nonreferred larger cohort is needed to confirm our preliminary findings. Additionally, the outcomes after posterior fossa decompression of the CM1 are variable. The SDB in some patients will resolve postdecompression, others may improve but still require either invasive or noninvasive respiratory support, and some will experience a worsening of SDB (35-37). Therefore, ongoing surveillance of these children, even after surgical and medical interventions, is paramount.

Our retrospective study had several limitations. First, the children included in the present study were a referred population, which may account for the high prevalence of SDB. Although the majority of children with CM1s are referred for sleep evaluation, it is not known whether there are differences in PSG results between referred and nonreferred children. It is not known whether children without symptoms have a similar prevalence of SDB. Symptoms are not an adequate screen for SDB in this population, especially in children with CSA, who would be potentially missed if symptoms alone were an indication for PSG. A needed next step is a prospective evaluation in our centre of all children with newly diagnosed CM1 on CNS imaging. Furthermore, being a single-centre study, our results may not be generalizable to other centres. Canadian centres may have different surgical approaches to offering posterior fossa decompression to children with CM1. However, equally important is that the access to PSG varies considerably across the country, with many pediatric academic centres not having access to PSG whatsoever. It is not clear to us whether these children are being studied in adult sleep laboratories or not being studied at all. To answer this question, we are planning a national survey to explore the referral patterns of pediatric neurosurgeons for PSG in children with CM1.

\section{SUMMARY}

We report a high prevalence of SDB in a large pediatric cohort with CM1, which challenges conventional dogma that CM1 is a congenital disease with 'adult onset'. Additionally, we have demonstrated that OSA is the most common type of SDB in a pediatric cohort with CM1. The present study was meant to illustrate the overall trends among clinical symptoms, radiographic findings and PSG results in a large, exclusively pediatric cohort. Our results suggest a relationship between the extent of cerebellar tonsillar herniation and OSA. However, further prospective studies, which include neurophysiological assessment, are needed to further translate the CNS imaging findings to the PSG readout. Furthermore, a Canadian registry is needed to design and implement a programmatic approach for this medically complex population to ensure early recognition of 
the disease and timely management to ensure best practice for these children and their families.

ACKNOWLEDGEMENTS: Writing of the protocol: RA, IN; data collection: RA, PS, AS and RP; data analysis: RA, CM; writing of the manuscript: RA, IN, SA and JD; editing of the manuscript: RA, IN, SA and JD.

\section{APPENDIX 1}

\section{Clinical symptoms at the time of polysomnography}

\begin{tabular}{lc}
\hline Clinical symptom & All Chiari I \\
patients ( $\mathbf{n}=68)$ \\
\hline Respiratory (total with at least one symptom) & $64 / 66(97)$ \\
Snoring & $43 / 68(63)$ \\
Gasping & $27 / 65(41)$ \\
Witnessed apnea & $24 / 65(37)$ \\
Mouth breathing & $56 / 64(88)$ \\
Blue spells & $5 / 65(7.7)$ \\
Restless sleep & $52 / 65(80)$ \\
Coughs & $33 / 63(52)$ \\
Daytime sleepiness & $55 / 63(87)$ \\
Nocturnal enuresis & $28 / 63(44)$ \\
Neurological (total with at least one symptom) & $58 / 68(85)$ \\
Developmental delay & $32 / 68(47)$ \\
Seizures & $3 / 68(4)$ \\
Headaches & $34 / 68(50)$ \\
Visual changes & $9 / 68(13)$ \\
Hearing loss & $10 / 68(15)$ \\
Vocal cord paralysis & $1 / 68(1)$ \\
Sensory changes of extremities & $4 / 68(6)$ \\
Motor changes of extremities & $6 / 70(9)$ \\
Gait or balance abnormalities & $14 / 68(21)$ \\
Bladder dysfunction & $1 / 68(1)$ \\
\hline &
\end{tabular}

Data presented as $n / n$ (\%)

\section{REFERENCES}

1. Botelho RV, Bittencourt LR, Rotta JM, Tufik S. A prospective controlled study of sleep respiratory events in patients with craniovertebral junction malformation. J Neurosurg 2003;996:1004-9.

2. Omer S, al-Kawi MZ, Bohlega S, Bouchama A, McLean D. Respiratory arrest: A complication of Arnold-Chiari malformation in adults. Eur Neurol 1996;361:36-8.

3. Tapia IE, Marcus CL. Newer treatment modalities for pediatric obstructive sleep apnea. Paediatr Respir Rev 2013;143:199-203.

4. Gozal D, Kheirandish-Gozal L, Serpero LD, Sans Capdevila O, Dayyat E. Obstructive sleep apnea and endothelial function in school-aged nonobese children: Effect of adenotonsillectomy. Circulation 2007;11620:2307-14.

5. Gozal D, Lipton AJ, Jones KL. Circulating vascular endothelial growth factor levels in patients with obstructive sleep apnea. Sleep 2002;251:59-65.

6. Chervin RD, Ruzicka DL, Giordani BJ, et al. Sleep-disordered breathing, behavior, and cognition in children before and after adenotonsillectomy. Pediatrics 2006;1174:e769-78.

7. Marcus CL, Carroll JL, Koerner CB, Hamer A, Lutz J, Loughlin GM. Determinants of growth in children with the obstructive sleep apnea syndrome. J Pediatr 1994;1254:556-62.

8. Marcus CL, Greene MG, Carroll JL. Blood pressure in children with obstructive sleep apnea. Am J Respir Crit Care Med 1998;1574 Pt 1:1098-103.

9. Amin RS, Carroll JL, Jeffries JL, et al. Twenty-four-hour ambulatory blood pressure in children with sleep-disordered breathing. Am J Respir Crit Care Med 2004;1698:950-6.

10. Amin RS, Kimball TR, Bean JA, et al. Left ventricular hypertrophy and abnormal ventricular geometry in children and adolescents with obstructive sleep apnea. Am J Respir Crit Care Med 2002;16510:1395-9.

\section{APPENDIX 2}

Nocturnal polysomnography findings in subjects with magnetic resonance imaging (MRI) findings of effacement versus no effacement

\begin{tabular}{|c|c|c|c|}
\hline \multirow[b]{2}{*}{ Variable } & \multicolumn{2}{|c|}{ MRI findings } & \multirow[b]{2}{*}{$\mathbf{P}$} \\
\hline & Effaced $(n=33)$ & Noneffaced $(n=35)$ & \\
\hline Central apnea index & $0.7(0.2-2.2)$ & $0.7(0.03-2.23)$ & 0.9 \\
\hline $\begin{array}{c}\text { Obstructive apnea- } \\
\text { hypopnea index }\end{array}$ & $0.6(0.2-1.12)$ & $0.9(0.1-3.9)$ & 0.42 \\
\hline $\begin{array}{l}\text { Total apnea-hypopnea } \\
\text { index }\end{array}$ & $1.3(0.7-4.7)$ & $2.1(0.8-7.9)$ & 0.25 \\
\hline
\end{tabular}

11. Miman MC, Kirazli T, Ozyurek R. Doppler echocardiography in adenotonsillar hypertrophy. Int J Pediatr Otorhinolaryngol 2000;541:21-6.

12. Tal A, Leiberman A, Margulis G, Sofer S. Ventricular dysfunction in children with obstructive sleep apnea: radionuclide assessment. Pediatr Pulmonol 1988;43:139-43.

13. Botelho RV, Bittencourt LR, Rotta JM, Tufik S. Polysomnographic respiratory findings in patients with Arnold-Chiari type I malformation and basilar invagination, with or without syringomyelia: Preliminary report of a series of cases. Neurosurg Rev 2000;233:151-5.

14. Botelho RV, Bittencourt LR, Rotta JM, Tufik S. The effects of posterior fossa decompressive surgery in adult patients with Chiari malformation and sleep apnea. J Neurosurg 2010;1124:800-7.

15. Dauvilliers Y, Stal V, Abril B, et al. Chiari malformation and sleep related breathing disorders. J Neurol Neurosurg Psychiatry 2007;7812:1344-8.

16. Losurdo A, Dittoni S, Testani E, et al. Sleep disordered breathing in children and adolescents with Chiari malformation type I. J Clin Sleep Med 2013;94:371-7.

17. Iber C A-IS, Chesson A, Quan S; for the American Academy of Sleep Medicine, eds. The AASM Manual for the Scoring of Sleep and Associated Events: Rules, Terminology and Technical Specifications, 1st edn. Westchester: American Academy of Slepe Medicine; 2007.

18. Montgomery-Downs HE, O’Brien LM, Gulliver TE, Gozal D. Polysomnographic characteristics in normal preschool and early school-aged children. Pediatrics 2006;1173:741-53.

19. Traeger N, Schultz B, Pollock AN, Mason T, Marcus CL, Arens R. Polysomnographic values in children 2-9 years old: Additional data and review of the literature. Pediatr Pulmonol 2005;401:22-30.

20. Marcus CL, Brooks LJ, Draper KA, et al. Diagnosis and management of childhood obstructive sleep apnea syndrome. Pediatrics 2012;1303:e714-55.

21. Dhamija R, Wetjen NM, Slocumb NL, Mandrekar J, Kotagal S. The role of nocturnal polysomnography in assessing children with Chiari type I malformation. Clin Neurol Neurosurg 2013;1159:1837-41.

22. Khatwa U, Ramgopal S, Mylavarapu A, et al. MRI findings and sleep apnea in children with Chiari I malformation. Pediatr Neurol 2013;484:299-307.

23. Rabec C, Laurent G, Baudouin N, et al. Central sleep apnoea in Arnold-Chiari malformation: Evidence of pathophysiological heterogeneity. Eur Respir J 1998;126:1482-5.

24. Bokinsky GE, Hudson LD, Weil JV. Impaired peripheral chemosensitivity and acute respiratory failure in Arnold-Chiari malformation and syringomyelia. N Engl J Med.1973;28818:947-8.

25. Bullock R, Todd NV, Easton J, Hadley D. Isolated central respiratory failure due to syringomyelia and Arnold-Chiari malformation. BMJ 1988;2976661:1448-9.

26. Xie A, Rutherford R, Rankin F, Wong B, Bradley TD. Hypocapnia and increased ventilatory responsiveness in patients with idiopathic central sleep apnea. Am J Respir Crit Care Med 1995;1526:1950-5.

27. Hanly PJ. Mechanisms and management of central sleep apnea. Lung 1992;1701:1-17.

28. De Backer WA. Central sleep apnoea, pathogenesis and treatment: An overview and perspective. Eur Respir J 1995;88:1372-83.

29. Dobkin BH. The adult Chiari malformation. Bull Los Angeles Neurol Soc 1977;421:23-7. 
30. Tsara V, Serasli E, Kimiskidis V, et al. Acute respiratory failure and sleep-disordered breathing in Arnold-Chiari malformation. Clin Neurol Neurosurg 2005;1076:521-4.

31. Riva D, Usilla A, Saletti V, Esposito S, Bulgheroni S. Can Chiari malformation negatively affect higher mental functioning in developmental age? Neurol Sci 2011;(32 Suppl 3):S307-9.

32. Prilipko O, Dehdashti AR, Zaim S, Seeck M. Orthostatic intolerance and syncope associated with Chiari type I malformation. J Neurol Neurosurg Psychiatry 2005;767:1034-6.

33. Wealthall SR, Whittaker GE, Greenwood N. The relationship of apnoea and stridor in spina bifida to other unexplained infant deaths. Dev Med Child Neurol 1974;166(Suppl 32):107-16.

34. Aurora RN, Lamm CI, Zak RS, et al. Practice parameters for the non-respiratory indications for polysomnography and multiple sleep latency testing for children. Sleep 2012;3511:1467-73.
35. Arcaya J, Cacho J, Del Campo F, Grande J, Maillo A. Arnold-Chiari malformation associated with sleep apnea and central dysregulation of arterial pressure.

Acta Neurol Scand 1993;883:224-6.

36. Miyamoto M, Miyamoto T, Hirata K, Katayama S. A case of Arnold-Chiari Type I malformation presenting with dysrhythmic breathing during sleep. Psychiatry Clin Neurosci 1998;522:212-6.

37. Ely EW, McCall WV, Haponik EF. Multifactorial obstructive sleep apnea in a patient with Chiari malformation. J Neurol Sci 1994;1262:232-6. 


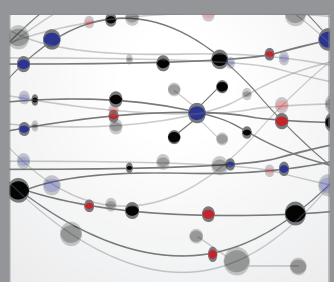

The Scientific World Journal
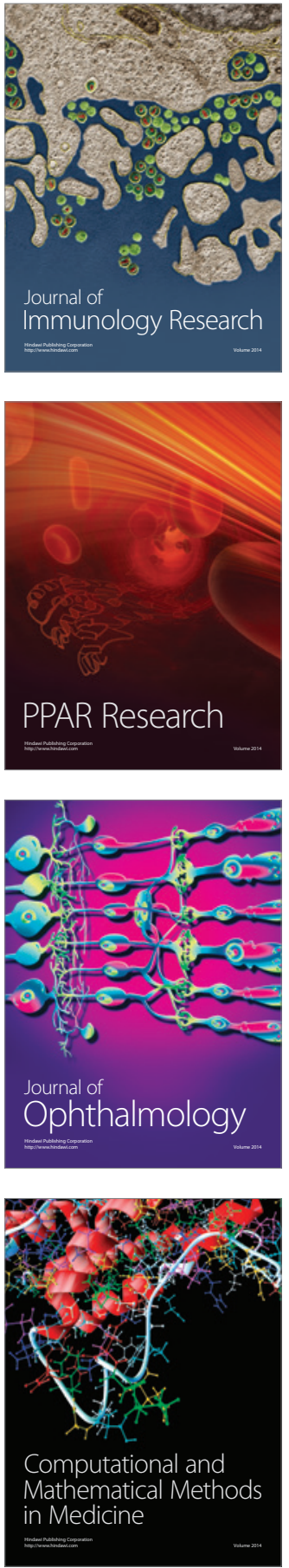

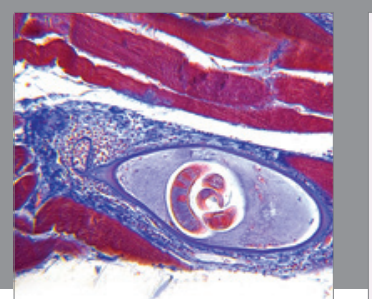

Gastroenterology Research and Practice

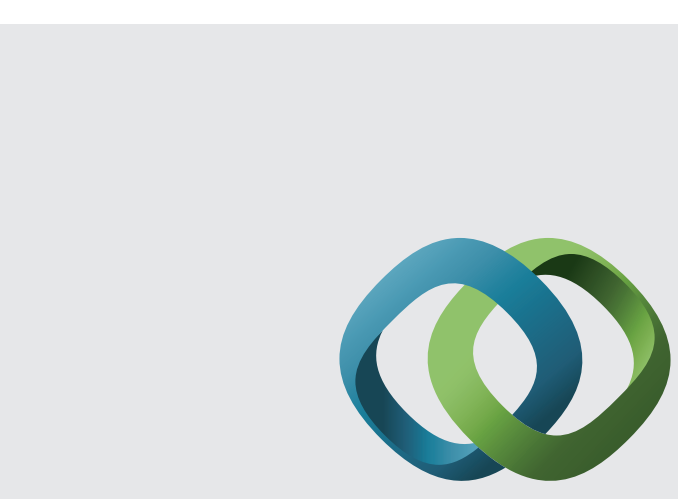

\section{Hindawi}

Submit your manuscripts at

http://www.hindawi.com
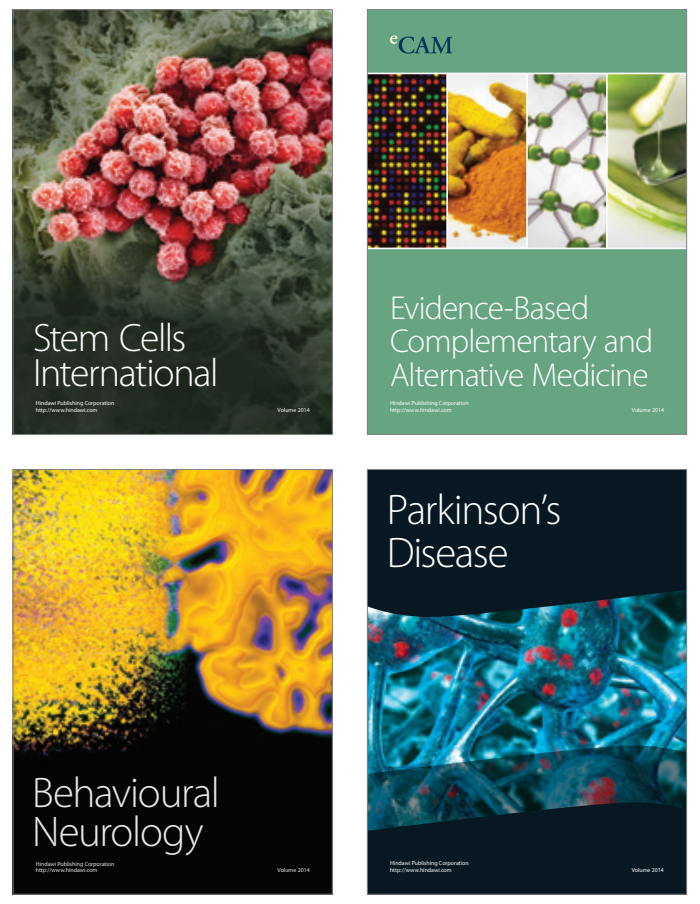
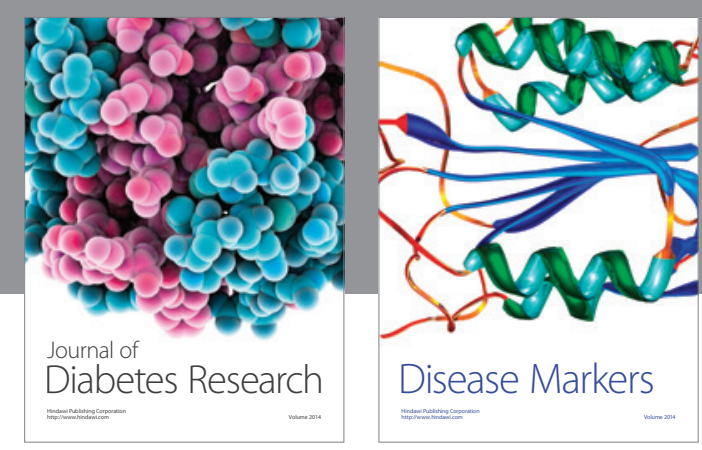

Disease Markers
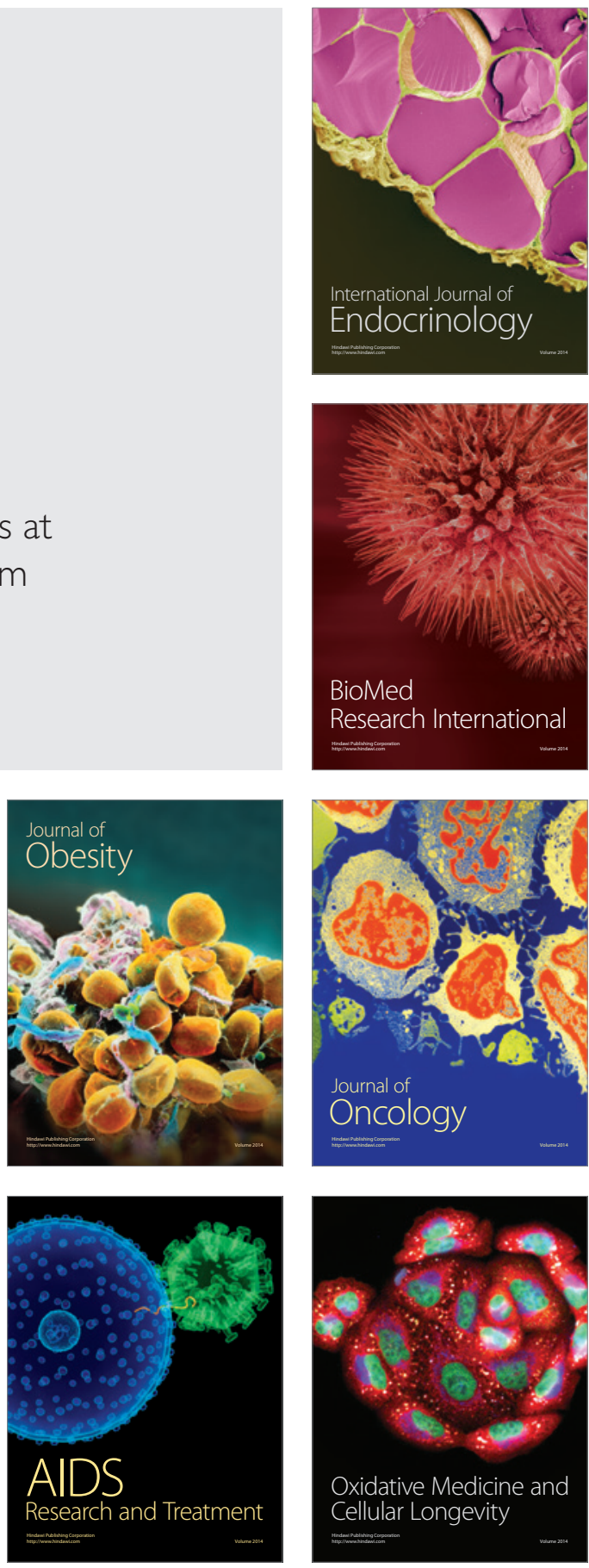